\title{
Determination of leaf area coefficient in sunflower
}

\author{
A. S. Rodrigues Pereira \\ Unilever Research Duiven, Zevenaar, the Netherlands
}

Accepted: 25 July 1977

Key words: leaf area, sunflower

\section{Summary}

For our studies on the relationship between photosynthetic capacity and yield components in sunflower we required a method for estimating leaf area. To this end use of the leaf area coefficient (LAC), that is the quotient area/(length $\times$ maximum width), has been evaluated. We found that LAC may be a function of leaf position and plant density, depending on the sunflower variety concerned. For the Russian sunflower cultivar Armavirec, LAC is independent of leaf position and plant density. For the Rumanian hybrid HS 18, LAC is dependent on leaf position but not plant density. For the French hybrid INRA 4701, LAC depends on both leaf position and plant density.

Even in the latter case, the LAC can be a useful aid in leaf area estimation.

\section{Introduction}

In our study of the relationship between photosynthetic capacity and yield components in sunflower we wanted an accurate method for the determination of leaf area. There are several methods available (Vivekanandan et al., 1972) the choice of which depends on their ease of application and the need to measure other parameters (e.g. shape, uniformity, duration).

The method in which leaf area is determined as the product of length, maximum width and a third factor: the leaf area coefficient, is convenient in practice and the said dimensions can be measured on the plant more than once during its lifetime. The leaf area coefficient is simple and constant in monocotyledonous plants such as sorghum and maize, the leaves of which are more or less of the same shape at all sizes and in all circumstances, but in dicotyledons such as sunflowers it can be influenced by several factors. In preliminary experiments with the sunflower hybrid INRA 4701, for instance, both leaf area and leaf area coefficient varied with the position of the leaf on the stem (Fig. 1.). We have therefore investigated whether and, if so, to what extent, the leaf area and leaf area coefficient in the sunflower are influenced by choice of variety, plant density and leaf position. 


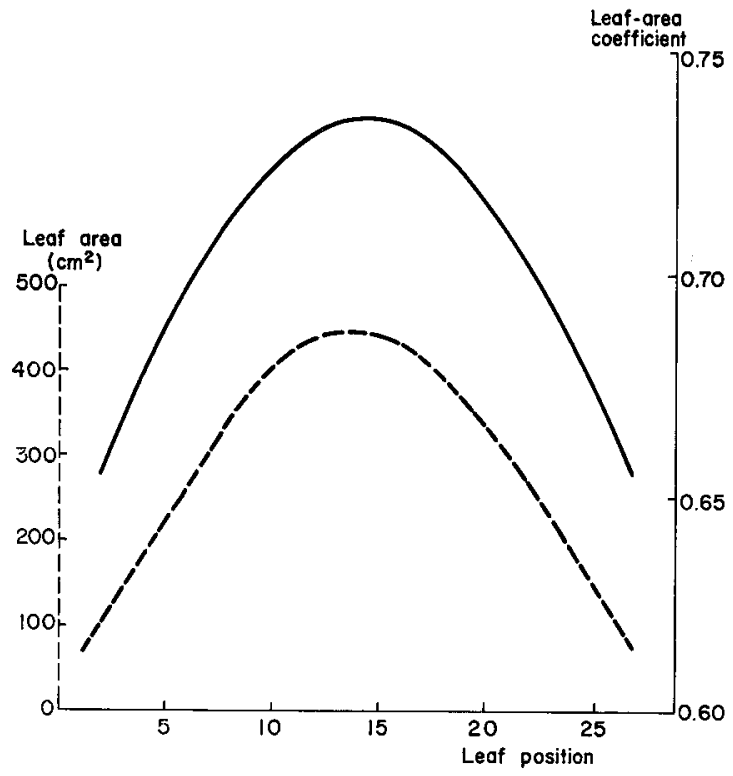

Fig. 1. Leaf area (dashed line) and leaf area coefficient as function of leaf position for the sunflower INRA 4701. (Preliminary trial in 1973 season, plant density 7 plants/ $\mathrm{m}^{2}$; curves based on averages of 20 plants).

\section{Material and methods}

Three varieties were tested, namely the French hybrid INRA 4701, the Rumanian hybrid HS 18, and the Russian cultivar Armavirec. A split-plot restriction was used with varieties as main plots and densities as subplots. All treatments were replicated. Each plot comprised 10 rows, $50 \mathrm{~cm}$ apart and $36 \mathrm{~m}$ long. Subplots included all ten rows and were 5, 4 or $3 \mathrm{~m}$ long. Within the rows the plants were spaced 40, 20 and $13.5 \mathrm{~cm}$, respectively, corresponding to densities of 5,10 and $15 \mathrm{plants} / \mathrm{m}^{2}$. Replicates were sown on 25 April and 5 May 1974. From each subplot 3 plants were harvested at the beginning of flowering. The leaves were numbered from the bottom to the top (this number being called the leaf position, $p$ ) and blue-printed on photo-sensitized paper. Length and maximum width of leaf blueprints were measured and their outline planimetered. Each plant had about 25 leaves; the lowest (about 5 to 7) were often missing at the time of harvest. In all about 1400 leaves were measured.

No systematic differences were found between the two replicates with respect to the mean leaf area coefficients. So the 6 plants for a particular combination of variety and plant density were pooled in all instances.

Leaf area and leaf area coefficient were plotted as functions of leaf position and quadratic equations were derived for the best-fit curves. Regression coefficients were established for all nine treatments separately. This was also done for the three main-plot treatments (varieties), and it was considered whether significant information was lost when the main-plot regression coefficients were used for the various densities. 


\section{A. S. RODRIGUES PEREIRA}

\section{Results}

\section{Leaf area}

Significant information on leaf area was lost when only the main-plot regression coefficients were used to predict the curves for the various plant densities. Thus leaf area depends not only on leaf position but also on plant density in all three varieties (Fig. 2). Therefore a formula which describes leaf area as a function of leaf position is only valid for one plant density in one growing season and on one growing site. Under such narrowly defined conditions one can, by determining the areas of, say, 6 to 8 leaves at different positions on about 5 plants, assess the leaf area of all plants of that particular plot with reasonable certainty.

\section{Leaf area coefficient}

Pooled regression analysis showed that for the variety Armavirec the leaf area coefficient is entirely independent of both leaf position and plant density (confidence level $95 \%$ ). Its value for Armavirec is $0.657 \pm 0.046$.

For hybrid HS 18, the leaf area coefficient varied with leaf position but was independent of plant density, at least between 5 and 15 plants $/ \mathrm{m}^{2}$.

The correlation coefficient (i.e. the leaf-area coefficient, LAC) between leaf area (Y) and the product of the length (l) and maximum width (w) of the leaf is a quadratic function of the leaf position, $\mathrm{p}$ :

$\left(\frac{\mathrm{Y}}{\mathrm{I} \times \mathrm{w}}\right)_{\mathrm{HS} 18}=\mathrm{LAC}_{\mathrm{HS} 18}=0.00975 \mathrm{p}-0.00035 \mathrm{p}^{2}+0.6731$
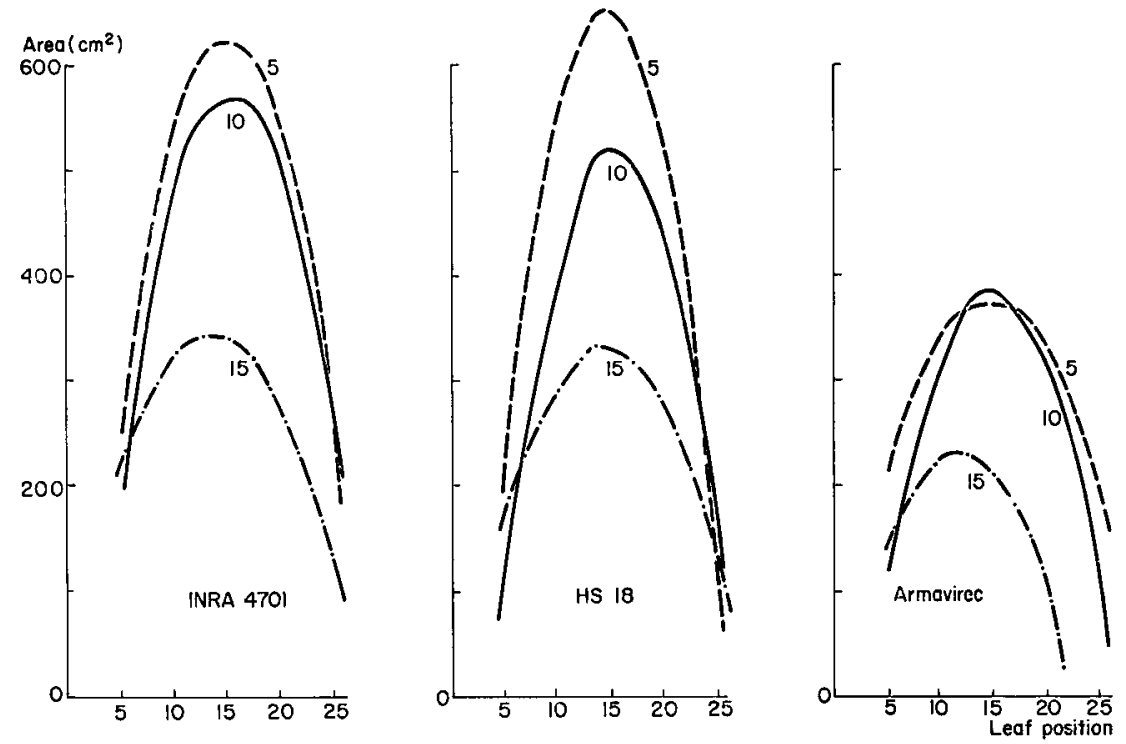

Fig. 2. Leaf area as a function of leaf position for the sunflower varieties INRA 4701, HS 18 and Armavirec at plant densities of 5, 10 and 15 per $\mathrm{m}^{2}$. 


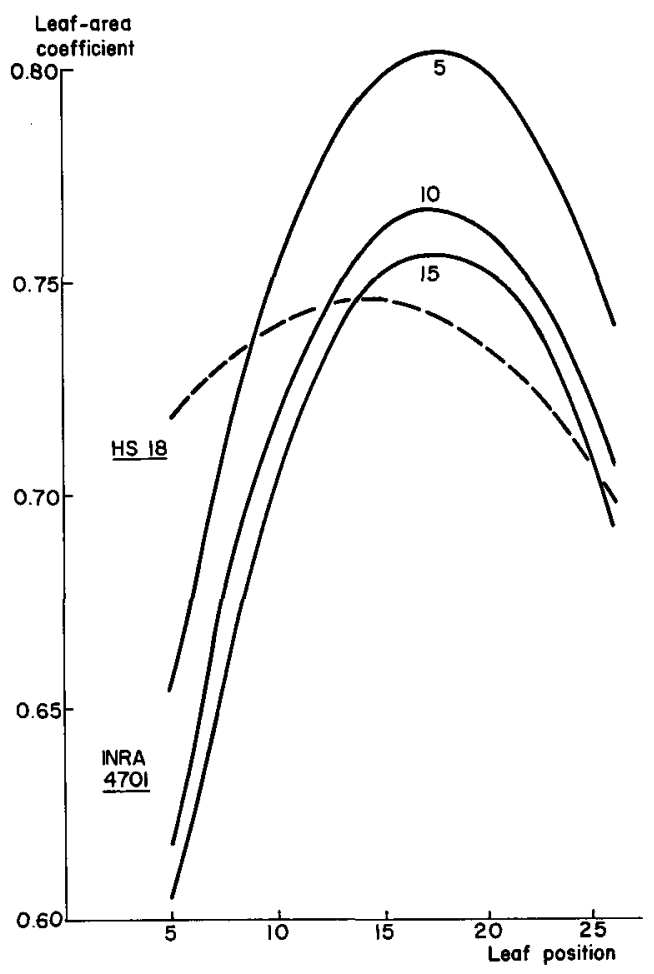

Fig. 3. Leaf area coefficient as a function of leaf position for HS 18 (for all plant densities tested) and for INRA 4701 at plant densities of 5, 10 and 15 per $\mathrm{m}^{2}$.

In INRA 4701 the leaf-area coefficient is not only influenced by leaf position but also by plant density. For each density separate regression equations have to be derived; for our trial these equations would be expressed as follows:

$\left(\frac{\mathrm{Y}}{1 \times \mathrm{W}}\right)_{\text {INRA 4701 }}=$ LAC $_{\text {INRA 4701 }}=0.0334 \mathrm{p}-0.00095 \mathrm{p}^{2}+\mathrm{c}$

with $\mathrm{c}=0.5107,0.4745$ or 0.4627 for 5,10 or 15 plants $/ \mathrm{m}^{2}$, respectively.

The leaf area coefficients for HS 18 and INRA 4701 are plotted against leaf position in Fig. 3. Comparison of the plot for INRA 4701 in Fig. 3 with that in Fig. 1 demonstrates that leaf area coefficient is also affected by growing season and site.

\section{Discussion}

It is commonly supposed that correlating leaf area with the product of length and maximum width of the leaves in dicotyledons is less easy than in monocotyledons. Our results indicate, however, that there are sunflower varieties in which the leaf area coefficient is constant.

Dependence of leaf area on leaf position, as found in the three sunflower varieties in this trial, has previously been observed in sorghum (Stickler et al., 1961). In other 
studies on sorghum and maize (Krishnamurthy et al., 1974; McKee, 1964; Whigham $\&$ Woolley, 1974) the influence of plant density was not considered. Thus the relation for monocotyledons may not be always as simple as has been assumed.

The extent to which the leaf area coefficient is constant and independent of plant density and leaf position might be considered as a measure for the stability of leaf form. Thus in INRA 4701 the form of the leaves is less stable than in HS 18 or Armavirec or, in other words, more flexible. If flexibility of leaf shape could be taken as a measure for the adaptability of the plant in general, we would expect INRA 4701 to be less affected by adverse growing conditions than the other two varieties.

For Armavirec leaf area coefficient can be derived from measurements on a single representative leaf for several plants. For HS 18, the coefficient is dependent on leaf position and therefore has to be derived from measurements on about 5 to 8 different leaves in each of several plants. For INRA 4701, the coefficient also depends on plant density; this necessitates measuring about 8 leaves of each of several plants for each plant density.

\section{Conclusion}

Knowledge of leaf area coefficient provides a convenient means of calculating the leaf area of sunflower from measurements of the length and maximum width of leaves. Depending on the variety in question the coefficient may vary according to leaf position and plant density. This influences the total number of leaves to be measured for a reliable estimate of leaf area.

\section{References}

Krishnammurthy, K., M. K. Jagannath, B. G. Rajashekara \& G. Ragunatha, 1974. Estimation of leaf area in grain sorghum from single leaf measurements. Agron. J. 66: 544-545.

McKee, G. W., 1964. A coefficient for computing leaf area in hybrid corn. Agron. J. 56: 240-241.

Stickler, F. C., S. Wearden \& A. W. Pauli, 1961. Leaf area determination in grain sorghum. Agron. J. 53: 187-188.

Vivekanandan, A. S., H. P. M. Gunasena \& T. Sivanayagam, 1972. Statistical evaluation of the accuracy of three techniques used in the estimation of leaf area of crop plants. Indian J. agric. Sci. 42: 857-860.

Whigham, D. K. \& D. G. Woolley, 1974. Effect of leaf orientation, leaf area, and plant densities on corn production. Agron. J. 66: 482-486. 